\title{
Innovation-driven Development and Supply-side Structural Reform in Northeast China
}

\author{
Xiao-Juan LIU ${ }^{1, a}$ and Zhen GUO ${ }^{2, b, *}$ \\ ${ }^{1,2}$ Harbin Univ. of Commerce, Harbin, Heilongjiang, 150028, China \\ aguozhenhrb@163.com, ${ }^{\mathrm{b}} 1179571765 @ q q . c o m$
}

Keywords: Northeast Region of China, Innovation-driven Development, Supply-side Structural Reform, Structural Adjustment.

\begin{abstract}
This paper studies the interactive mechanism on innovation-driven development and supply-side structural reform, and combined with the problems that exist in northeast China, concludes that the revitalization of northeast China should rely on deepening supply-side structural reform, and by implementing the strategies of innovation-driven development, innovate development ideas, build systems and mechanisms stimulating innovation, and actively promote structure rearrangement in order to improve the development vigor, endogenous motivation, and overall competitiveness of northeast old industrial base.
\end{abstract}

\section{Introduction}

The Northeast China, in addition to Liaoning, Jilin, Heilongjiang provinces, includes Hulunbeir city of Inner Mongolia, Tongliao city, Chifeng city and Hinggan League. Because of the lagging reform and opening up in northeast China, the state-owned economy accounts for a high proportion and enterprises lack development vitality, besides, manufacturing competitiveness is declining, and the services level is far below the national level, which is generally considered "the ownership structure based on public ownership and the industrial structure with dominating second industry". In recent two years, the foreign demand of coal, petroleum, and steel slows down, the prices of that are falling as well, which cause great difficulties to the basic industry development, and the industrialized idea and level in rural areas seriously lag behind, especially in counties. The whole northeast region's economic growth continues to fall away [1].

The northeast China should regard the comprehensive revitalization of the regional economy as key point-focus on structure adjustment, employment expanding and industrial competitiveness improving. The structural adjustment that the northeast China is facing, includes not only the industrial structure optimization and upgrading, but also demand structure that includes domestic and overseas demand structure, factor input structure, income distribution structure, urban-rural structure, regional structure, ownership structure and so on. Only we accelerate the market-orient system and mechanism reform to achieve interactive coordination on innovation-driven development and supply-side structural reform, nationwide entrepreneurship and innovation systems and mechanisms can be established, innovation vigor can be scrambled to burst, innovation productions can be converted, and innovation value can be embodied to provide a lasting impetus for economic and social development. 


\section{The Interactive Mechanism between Innovation-driven Development and Supply-side Structural Reform}

\section{Innovation-driven Development will lead to Supply-side Structural Reform}

The main body of supply-side reform is the enterprise, however, enterprises in northeast China lack vitality and their market share continuously decreases. In a changing environment with internal factors limitation and external economic pressure, only by systems and mechanisms innovation to reduce transaction costs, could the needs of the market be meet, and enterprises finally realize the innovation-driven development based on quality and efficiency, to be more precise(1) induce market demands by means of product innovation. Product innovation is market - oriented, and enterprises market position can be improved only when develop product innovation strategies based on market needs (2) increase efficiencies and reduce costs with technological innovation. Technological innovation can drive the optimal allocation of production elements of the whole industry and form the scale of production ability to promote enterprises core competitiveness changing from price competition to $R \& D$ competition and service, quality competition.(3) enhance the dynamics of enterprise development by management innovation. Establish modern enterprise systems, and reasonably arrange product development, production, circulation, sales and services and other series of value creation activities through enterprise management innovation to stimulate the enterprise vitality in order to survive in the fierce market competition [2].

\section{Innovation-driven Development Proves to be a Key Variable to Supply-side Structural Reform}

In essence, the fundamental cause of mismatching China supply and demand is that current existing products and services do not adapt to increasing consumer demand with income level. The solution to this problem can only rely on innovation-driven development, that is, inject a bran-new combination of new productive factors and production condition into production system by means of production factors innovation, production innovation, technology innovation, system innovation so as to correct the factor allocation distortion and gradually reduce the invalid supply, expand the effective supply, and strengthen quality supply, therefore, innovation-driven development is a key variable to supply-side structural reform. Functions of innovation-drive development include: (1) Innovation-driven development is conducive to the optimization and upgrading of industrial structure. That modern agricultural development is still at a low level with inefficient operation, traditional manufacturing industries continuously expand the scale but lack of core competitiveness and some serious excess capacity, and strategic emerging industries lack key technologies and modern services have a relatively low proportion, currently, exist in northeast China. The way to solve these problems is that deepen supply-side structural reform through innovation-driven development, innovate industry development concept, improve industrial technology level, optimize the production mode, and improve production quality and competitiveness, thus the optimization and upgrading of industrial structure will be finally realized (2) Innovation-driven development is beneficial to the balance of supply and demand. The reason of weak domestic consumption is that, continuously expanding production capacity with traditional production mode does not match the actual domestic consumption demand, meanwhile, the international market demand is downward, and all these ultimately result in excess capacity. As resident's income increases, consumer demand gradually 
changes into diversification, individuation, and security, however, now domestic low-end commodities over production is universal but high-quality commodities supply is in shortage, which must be solved by implementing innovative strategy and deepening the supply-side structural reform. We need to develop producer services, promote the upgrading of manufacturing industry, and construct modern agricultural production and management system to realize the effective docking between the production and market, and form a transmission mechanism that innovation drives effective supply, and effective supply in turn stimulates effective demand, to promote the balance of supply and demand[3].

\section{Supply-side Structural Reform Surely Lays a Solid Foundation for Realizing Innovation-driven Transformation Development}

The problems-slowing GDP growth, overcapacity, reduction of fiscal revenue, and the brain drain in the northeast region [4], are structural, some belong to demand side, but the main contradictions are in supply side. To promote supply-side structural reform should regard improving the quality and efficiency of supply system as the goal, intensify market reform in key areas, and perfect the market environment and mechanism of surviving the fittest to stimulate the microscopic vitality to the greatest extent. Mainly complete five tasks "cutting excessive industrial capacity, de-stocking, de-leverage, cost reduction, improving weakness", for laying a solid foundation for innovation-driven development. Through cutting excessive industrial capacity, zombie companies will go bankrupt or reorganize, thus industry supply will be optimized to realize the market supply and demand balance. Reducing the cost of the real economy enterprises is conducive to enhance enterprises development and innovation ability, pad out industry "short board" and fully improve industrial base capacity and international competitiveness, and promote the traditional industry transformation and also support the development of strategic emerging industries. In addition, the focus of funds and policies should be on the construction of modern agricultural industrial system and the improvement of agricultural science and technology innovation, which will expand agricultural innovation-driven space, and change agricultural development mode to promote agricultural modernization.

\section{Supply-side Structural Reform Helps to Build the Innovative Institutional Supply System}

Institutional supply is another important subject in supply side, and that realizing the system and mechanism innovation, needs to create institutional supply system that is conducive to innovation, which is the fundamental guarantee to realize the transformation and upgrading of China's industry and innovation-driven development. It is because the functions of market mechanism in the process of economic development are not brought into full play, economic vitality obeys the government order to a great extent rather than the market rules, thus the market cannot timely clear, and results in all kinds of structural contradictions, which requires innovating the institutional supply, that is, accelerate the construction of a service-oriented government, and purely fulfill the government basic duties through the top-level design innovation, systems and mechanisms innovation. Environment of business should be improved to quicken the development of civilian battalion economy, and especially for the northeast China, should create a better investment environment to attract more foreign investment. The enterprises should be regard as the main body of economic innovation-driven development, according to the requirements of structural reform, try to guide by functional industrial policies, and let entrepreneurs explore and 
grasp specific investment opportunities to create an effective supply and consumption market. Practice shows that the market selection is more effective, and only the government plans first and market operates, the complementary advantages between macro-control and market mechanism can be achieved.

\section{Strategies of Innovation-driven Development in Northeast China Based on Supply-side Structural Reform}

\section{Accelerate the Construction of New Systems and Mechanisms of Innovation-driven Development}

Promoting supply-side structural reform should focus on releasing and developing productive forces, especially through a series of effective system arrangement, accelerate the reform of market-orient systems and mechanisms and form new systems and mechanisms full of dynamics and orderly competition in order to realize the northeast China innovation-driven development. First, expedite the transformation of government functions to build a service-oriented government. Do efforts to solve the government directly allocate resources, excessive management and function dislocation, offside, and other issues. Construct "Leading Area" of transforming government function and innovating management system through establishing Dalian Jinshan District, Harbin District, Changchun district (Shenyang) and the German high-end equipment manufacturing industrial park to improve the administration and service methods of government with main points of providing better services for market participants, for instance, strengthen the policies, legal and information consulting services, the protection of intellectual property rights, college students employment services and the new generation of migrant workers skill training. Second, innovate public services mode and supply mechanisms for offering fair and accessible public services. The nation should support the northeastern region to play a leading and exploratory role in the comprehensive deepening of the SOE reform, perfect state-owned enterprises management modes and operation mechanisms and truly establish their dominant position in the market. The provinces, cities, counties, townships (town), village organizations should push forward in the overall way the development of private economy, and improve the business environment.

\section{Promote Transformation and Upgrading of Traditional Advantage Industries; Optimize Modern Industrial System}

Enterprises technological innovation abilities must be strengthened to promote the transformation and upgrading of traditional advantage industries. On one hand, joint innovation should be encouraged between the same industry to reduce the risk and cut the innovation cost, besides, improve the success rate of innovation based on displaying their respective advantages; on the other hand, joint innovation also should be carry out by upstream and downstream firms, and upgrade traditional advantage industries with advanced and applicable technologies, which helps to extend the industrial value chain and enhance the value space. The traditional advantage industries in Northeast China should actively participate in the research and development of home and abroad new technologies to seize the opportunities of technological innovation, and accurately grasp the strategic position of industrial transformation and upgrading under the new economic norm to develop e-commerce, supply chain logistics, internet banking and other emerging formats based on the development of local economy. The Northeast has the concentrated arable land, high soil quality, and high degree agricultural mechanization, thus can be the first to build a 
modern agricultural industrial system, production system, management system so as to become an important industry to support innovation-driven development.

\section{Speed up the Development of Modern Service Industry; Improve the Level of Outward-oriented Economy}

Guide equipment manufacturing industries transformation from the type of production manufacturing to production and services, and effectively improve their level of specialization in research and design, information technology services, e-commerce, business consulting, after-sales services, human resource services, and other key areas to enhance the enterprises value chain. We should strengthen the front-end production research and design of manufacturing industries and put a high value on market development and business model innovation to promote the integration of production and service to a new level, moreover, perfect after-sales services and develop its new formats to improve customer satisfaction, in addition, explore new kinds of financial products and services suitable for the characteristics of service industry to promote regional finance development. The northeast China should take the initiative to integrate and actively participate in the "The Belt and Road" strategy, strengthen interconnection with neighboring countries infrastructure, and construct an foreign cooperation platform oriented to Russia, Japan, Korea, North Korea, Mongolia to create new perspectives for cooperation in international production and equipment manufacturing industry, and steadily promote overseas investment in the agricultural sector, gradually advance the traditional agricultural enterprises expanding to the processing and circulation development, further ease the investment boundary for foreign investors to undertake foreign industry transfer, and encourage foreign investment more into advanced manufacturing, high-tech, energy-saving and environmental protection industry, modern services and other field.

\section{Reinforce the Enterprises Status as the Main Body of Innovation; Perfect the Mechanism of Innovation-driven Development}

Enterprises are having dominant effect in technological innovation, and should be encouraged to carry out the fundamental frontier innovative research to promote the integration of the science and technology, education, and the economic in order to further perfect the technical innovation system. (1) Improve the mechanisms of technological innovation and policy support, strengthen the support for emerging technologies research, optimize the finance allocation mechanism for the innovation, increase investment to basic research and original innovation, especially to the core technologies, and actively propel the construction of basic research platform to encourage the original innovation. (2) Establish the enterprise-oriented industrial technology innovation consortia and strengthen the Industry-University-Research cooperation to shorten the period from basic research to industrialization, moreover, straighten out the function and relationship that the market and the government play in the innovation activities, and actively display the guiding function of the market mechanism on the basic orientation, path selection and optimal allocation of innovation resources to technology research and development. The government should change its functions to cultivate a good environment for the public business and mass innovation, increase the support for innovative small and micro businesses to embark on a path of 'specialized, fined, peculiar and new', improve the corporate $\mathrm{R} \& \mathrm{D}$ cost plus and deduction policies, and encourage enterprises to develop new technology, new products, new services. 


\section{Conclusion}

The revitalization of northeast China should be out of the common mistaken ideas that study industry simply based on the industrial theory and just emphasize state-owned companies 'deprivation of distress', etc. What the northeast China faces, after all, are system and mechanism problems. So we should take supply-side structural reform as the key point, accelerate the pace of market-orient systems and mechanisms reform, innovate institutional supply, and make full use of resources, market and institutional advantages in northeast China to construct regional cooperative innovation community for releasing new innovative development kinetic energy and finally achieve the revitalization of northeast China old industrial bases.

\section{References}

[1] The National Development and Reform Commission, China's 13 the five - year Planning Law of National Economy and Society Development counseling textbook, M, People's Republishing House, 2016

[2] Jie Ling, Research on supply-side structure reform and strategies of China innovation-driven development, J. Reform and Strategy, 2016(7): 83-86.

[3] Jian Huang, on supply-side structure reform under the guidance of innovation-driven mind, J. Journal of Hebei University of Economy and Trade, 2016(5):12-17.

[4] Ming-hui Sun, countermeasures on the transformation of northeast traditional advantage industry, J. Forward Position, 2016(4): 64-69. 